\title{
Intraoperative radiotherapy in gynaecological and genito-urinary malignancies: focus on endometrial, cervical, renal, bladder and prostate cancers
}

\author{
Marco Krengli ${ }^{1,2^{*}}$, Carla Pisani ${ }^{1,2}$, Letizia Deantonio ${ }^{1,2}$, Daniela Surico ${ }^{1,3}$, Alessandro Volpe ${ }^{1,4}$, Nicola Surico ${ }^{1,3}$ \\ and Carlo Terrone $e^{1,4}$
}

\begin{abstract}
Intraoperative radiotherapy (IORT) refers to the delivery of a single radiation dose to a limited volume of tissue during a surgical procedure. A literature review was performed to analyze the role of IORT in gynaecological and genito-urinary cancer including endometrial, cervical, renal, bladder and prostate cancers.

Literature search was performed by Pubmed and Scopus, using the words "intraoperative radiotherapy/IORT", "gynaecological cancer", "uterine/endometrial cancer", "cervical/cervix cancer", "renal/kidney cancer", "bladder cancer" and "prostate cancer". Forty-seven articles were selected from the search databases, analyzed and briefly described.

Literature data show that IORT has been used to optimize local control rate in genito-urinary tumours mainly in retrospective studies. The results suggest that IORT could be advantageous in the setting of locally advanced and recurrent disease although further prospective trials are needed to confirm this findings.
\end{abstract}

Keywords: Intraoperative radiotherapy, Endometrial cancer, Cervical cancer, Renal cancer, Bladder cancer, Prostate cancer

\section{Background}

Intraoperative radiotherapy (IORT) refers to the delivery of a single large dose of radiation to a limited volume of tissue during a surgical procedure.

Radiotherapy (RT) has a major role in the management of most gynaecological and genito-urinary cancer as adjuvant or neoadjuvant treatment or as radical treatment in combination with chemotherapy or hormone therapy. IORT has the capability to increase the radiation dose with very limited or no increase of toxicity thanks to the target exposition during the surgical procedure. For this reason, IORT can be used in various settings of gynaecological

\footnotetext{
* Correspondence: marco.krengli@med.uniupo.it

'Department of Translational Medicine, University of Piemonte Orientale, Via Solaroli, 17-28100 Novara, Italy

${ }^{2}$ Department of Radiotherapy, University Hospital Maggiore della Carità,

Novara, Italy

Full list of author information is available at the end of the article
}

and genito-urinary tumours aiming at dose intensification and consequently at increasing tumour control rate.

IORT can be delivered using dedicated linear accelerator producing electron beams, X-rays sources delivering lowenergy radiation or high dose-rate brachytherapy units through catheters positioned in the tumour bed and loaded with iridium-192. In particular, electrons generated by linacs and brachytherapy sources can be conveniently used for IORT procedures in gynaecological and genito-urinary tumours.

Interestingly, the first IORT experience was indeed reported in 1905 for the treatment of a 33 year old woman affected by uterine carcinoma [1]. Over the following decades, IORT was increasingly used for several tumours including gynaecological and genitor-urinary malignancies.

In 1998, the International Society of Intraoperative Radiation Therapy (ISIORT) was founded in order to promote a scientific and professional approach to IORT activity. Among their other activities, ISIORT-Europe collected and 
recorded information regarding IORT treatments, including those of gynaecological and genito-urinary cancers, from the affiliated centres in a database registry $[2,3]$.

This review focuses on the use of IORT in genito-urinary malignancies, reporting tumour setting and outcome for endometrial, cervical, renal, bladder and prostate cancers.

\section{Research criteria}

Literature search was performed through Pubmed and Scopus databases by using the following key words: "intraoperative radiotherapy/IORT", "gynaecological cancer", "uterine/endometrial cancer", "cervical/cervix cancer", "renal/ kidney cancer", "bladder cancer" and "prostate cancer". Eighty-four articles were found from 1981 to 2015. Reviews and case reports were excluded as well as clinical series presented as abstract at conferences proceedings. Forty-seven articles were finally selected for the review.

\section{Endometrial and cervical cancers}

Patients with endometrial and cervical cancer are usually treated with surgery and RT with or without chemotherapy depending on risk factors. After primary treatment, the risk of local failure is up to $60 \%$ [4] and the options for a new treatment are surgery, RT when a reirradiation is feasible, and chemotherapy. After such treatments, disease control has been reported in $25-50 \%$ and $18-47 \%$ in patients with recurrent endometrial and cervical cancer, respectively [5]. In these recurrent patients, IORT after surgical resection can been considered to increase the probability of local control, especially when a repeated course of EBRT is not feasible. This treatment approach including IORT is reported in the NCCN guidelines with an evidence of category 3 [6].

The use of IORT in the management of endometrial and cervical cancer was explored in 15 studies, most of them analysing retrospectively patients affected by locally advanced primary and recurrent disease. The majority of articles reported on the clinical experience from the Mayo Clinic and the University Hospital Gregorio Marañón in Madrid [7-21] (Table 1). In these clinical series, IORT was delivered to the tumour bed with electrons in the majority of cases and with low $\mathrm{kV} x$-rays or brachytherapy through catheters implanted during the surgical procedure and uploaded with iridium wires in postoperative setting in selected patient series.

In endometrial cancer patients, limited loco-regional recurrences have a relatively high control rate of about $60 \%$ at 5 years either with pelvic exenteration or local EBRT in non-previously irradiated patients [22, 23]. In this tumour setting, the use of IORT was reported in retrospective studies [14, 15]. Dowdy et al. [14] found that radical resection of the pelvic sidewall with negative margins and IORT resulted in a relatively high overall survival rate (71\%) (Table 1). Awtrey et al. [15] reported that the addition of IORT to cytoreductive surgery in 27 recurrent endometrial cancer patients resulted in a 2-year disease free survival (DFS) rate of $78 \%$ versus $67 \%$ when IORT was not used, although this difference was not statistically significant. Based on these retrospective data, the addition of IORT to surgery could be proposed in patients with isolated endometrial cancer recurrences, especially when margins might be close or microscopically positive.

Patients with a loco-regional recurrence of cervical cancer and candidates for salvage surgery can undergo also IORT with the intent to sterilize the possible residual disease and improve the outcome. This approach was described in three series from Mahe et al. [20], Barney et al. [10] and Martinez-Monge et al. [16] who reported globally the results in 188 patients with recurrent cervical cancer. Intraoperative radiation dose ranged from 6 Gy to $30 \mathrm{~Gy}$, with higher doses in case of macroscopically positive margins (R2). Mahe et al. [20] reported a slightly higher local control, although statistically not-significant, in patients with radical resection versus those who received partial resection (27\% vs. $11 \%)$, Barney et al. [10] did not observe any influence of margins status for local control and Martinez-Monge et al. [16] reported a risk of distant metastases of $38 \%$ in patients with negative margins (R0) and $100 \%$ in those with macroscopic residual disease (R2). From these studies, it emerged that the status of the margins is the most important risk factor for treatment and the association of IORT seems to improve the probability of local control.

As far as locally advanced primary cervical cancer is concerned, two series treated by IORT are reported in the recent literature $[12,16]$. In both studies, patients underwent radical hysterectomy and 10-25 Gy IORT after neoadjuvant EBRT, concomitantly to chemotherapy, to a total dose of 50.4 Gy. In the Giorda's phase II trial, patients tolerated radio-chemotherapy quite well, but developed high incidence of toxicity (79\%) after surgery and IORT [12]. In the Martinez-Monge's retrospective series, $15 \%$ of side effects were related to IORT [16]. The available data suggests that this aggressive strategy is not advantageous in particular for the risk of severe side effects and that concomitant radio-chemotherapy alone should be considered the best treatment strategy in this patient setting [6].

In conclusion, literature data supports the use of IORT in recurrent endometrial and cervical cancer to improve local control whereas its use appears more controversial in primary locally advanced disease. The potential benefit of this approach is mainly based on retrospective mono-institutional studies and should be further verified by prospective possibly randomized trials investigating the potential advantage compared to EBRT alone.

\section{Renal cancer}

Historically, the standard therapy for renal cell carcinoma is radical nephrectomy. Local control and survival 


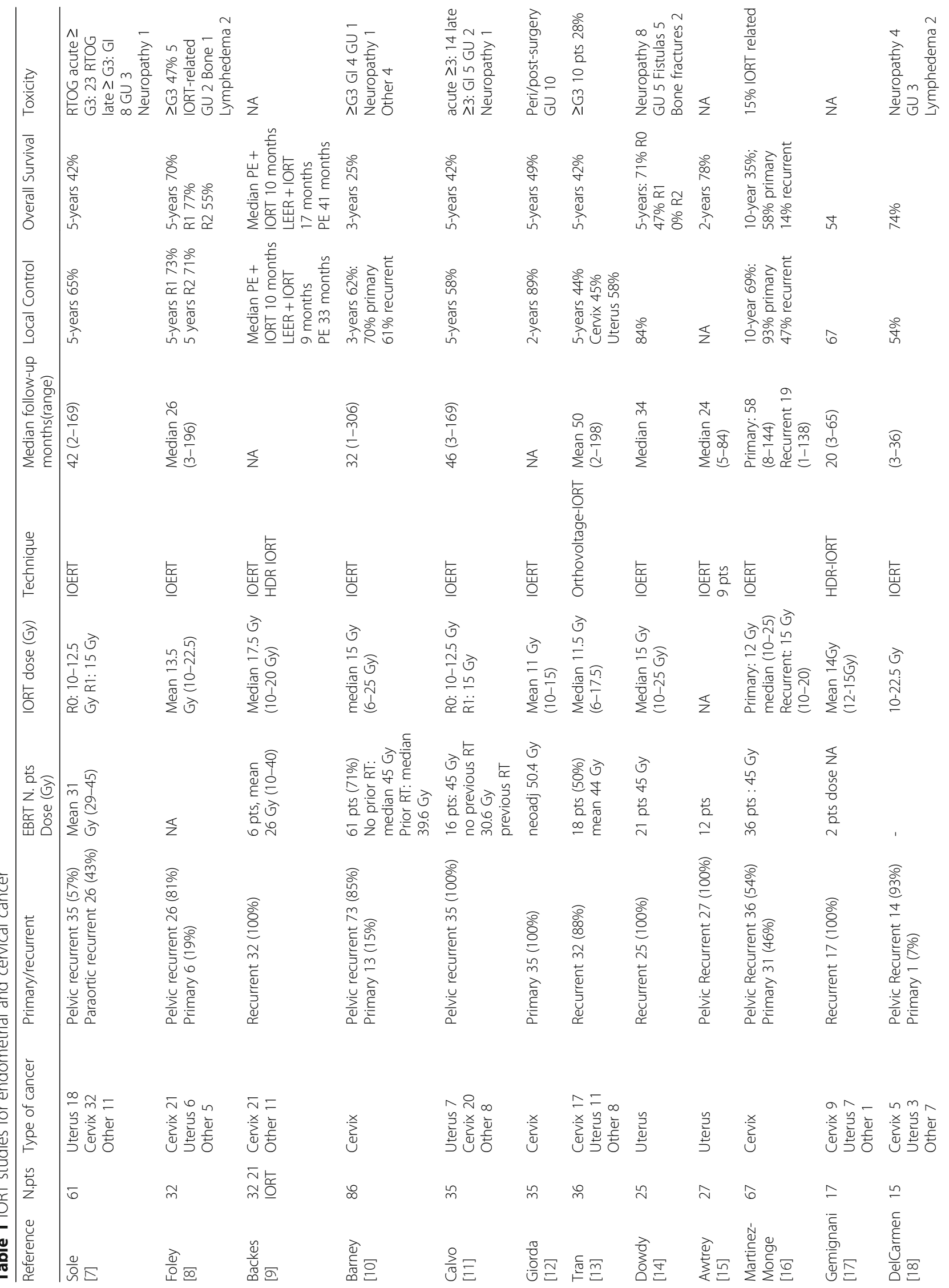




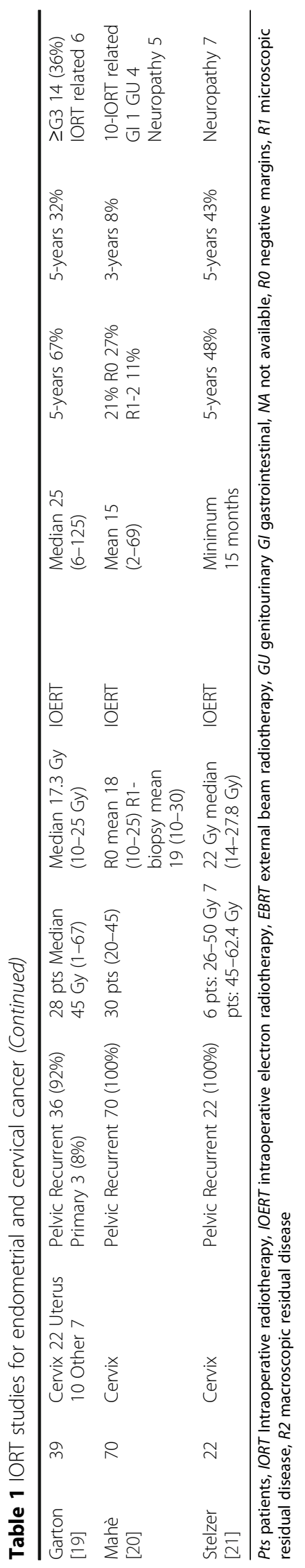


rates after surgery alone are satisfactory for T1-T2 N0 with rates of $90-100 \%$ and $80-90 \%$ at 5 years, respectively. The results are less favourable for locally advanced and $\mathrm{N}+$ disease, where the 5-year local control rate and overall survival rates are $70-80 \%$ and $0-40 \%$, respectively. In renal cancer, the isolated local recurrence after radical nephrectomy is uncommon (0.7-3.6\%) but it is associated with a poor prognosis. An aggressive surgical approach to local advanced or recurrent disease, possibly including the removal of the renal fascia and leading to negative margins, seems to improve outcome and prolong survival $[24,25]$.

Although renal cell carcinoma has traditionally been considered relatively radiation resistant, recent data using hypofractionation for primary or metastatic lesions suggest that this resistance can be overcome by high dose per fraction, as used in the IORT scenario [26].

The role of IORT in the management of renal cancer was explored in a number of retrospective studies with patients presenting with locally advanced primary or recurrent disease [27-33] (Table 2). IORT doses varied from 10 to 25 Gy depending on the amount of residual tumour after maximal resection and on the dose of the combined EBRT. All cases of these series were characterized by postoperative microscopic or macroscopic residual disease in the renal fossa. A more recent study [27] considered 98 patients with advanced or recurrent renal cell carcinoma treated with IORT at nine institutions. Preoperative or postoperative EBRT to a total dose of $40-50.5$ Gy was administered to $27 \%$ or $35 \%$ of patients, respectively. The median radiation dose administered with IORT was 15 Gy (range: 9.5-20 Gy). Overall survival and disease free survival rates at 5 years were quite similar and only $24 \%$ of relapses were local whereas $76 \%$ were distant. This fact suggests the potential benefit in local control when IORT is added. Similar results in terms of local control rates were reported in previous studies from other institutions (Table 2). In these series, the acute and late toxicity profile seems acceptable. Many studies, however, are characterized by a limited description of late side effects.

From all published data, although from retrospective series, it emerges that the addition of IORT to surgery and EBRT is associated with high rates of local control with acceptable toxicity. The best candidates could be untreated patients with large tumour volume and high risk of positive margins after radical nephrectomy and patients with locally recurrent tumours. The long-term prognosis is mainly related to the risk of onset of distant relapse that is quite common, especially in patients with recurrent disease. This fact advocates the need for additional systemic effective therapy.

\section{Bladder cancer}

The goals of treatment for invasive bladder cancer are high long-term overall and disease-free survival rates with acceptable functional outcome, however, radical cystectomy, that is nowadays the standard, needs urinary diversion and results in erectile impotence and infertility. In order to avoid these adverse effects and preserve quality of life, bladder-preserving treatments have been proposed as a viable option in selected patients [34]. Bladder preservation strategies for muscle invasive bladder cancer evolved over time from single modality to multimodality treatment approaches, including transurethral resection and chemo-radiation protocols. The use of an intraoperative radiation boost by brachytherapy or electrons may be advantageous for intensifying the dose and obtaining local control without compromising organ function.

From the literature databases, 15 studies using IORT by brachytherapy implants or electrons were selected for this review [35-49] (Table 3). Brachytherapy was the most used intra-operative modality and was employed either as a single treatment or as a boost dose combined with EBRT. It may represent a curative treatment for selected high-risk superficial and solitary muscle infiltrating tumours. Clinical target volume (CTV) typically includes the macroscopic disease or the tumour bed with safety margin to full thickness of the bladder wall.

All the studies about brachytherapy were retrospective analyses of single or multiple co-operative centres. In 2012, a multicentre survey [36], assessed the role of brachytherapy in 1040 patients with early stage bladder carcinoma in a muldisciplinary setting. Patients were treated by pre-operative EBRT and limited surgery with brachytherapy implant. From this analysis, it emerged that this approach can offer adequate results in terms of local control and overall survival in selected patients suitable (Table 3). In this regard, a careful patient selection is particularly important in relation to the nonnegligible probability of acute toxicity leading to fistulas or necrosis.

A recent systematic review with meta-regression analysis showed better results after brachytherapy than after cystectomy in terms of overall survival, but not in terms of causespecific survival in patients with muscle-invasive bladder cancer. The authors commented that this discrepancy can be explained at least in part by the differences in tumour stage between the two groups [50].

The integration of an IORT boost to the whole bladder in a multidisciplinary protocol combining neoadjuvant systemic chemotherapy, preoperative RT, and planned cystectomy has proven to be feasible in the Pamplona's series [44]. The mean sterilization rate of invasive bladder cancer, confirmed in pathologic studies by the cystectomy specimen, was $65 \%$, and seemed to be increased 


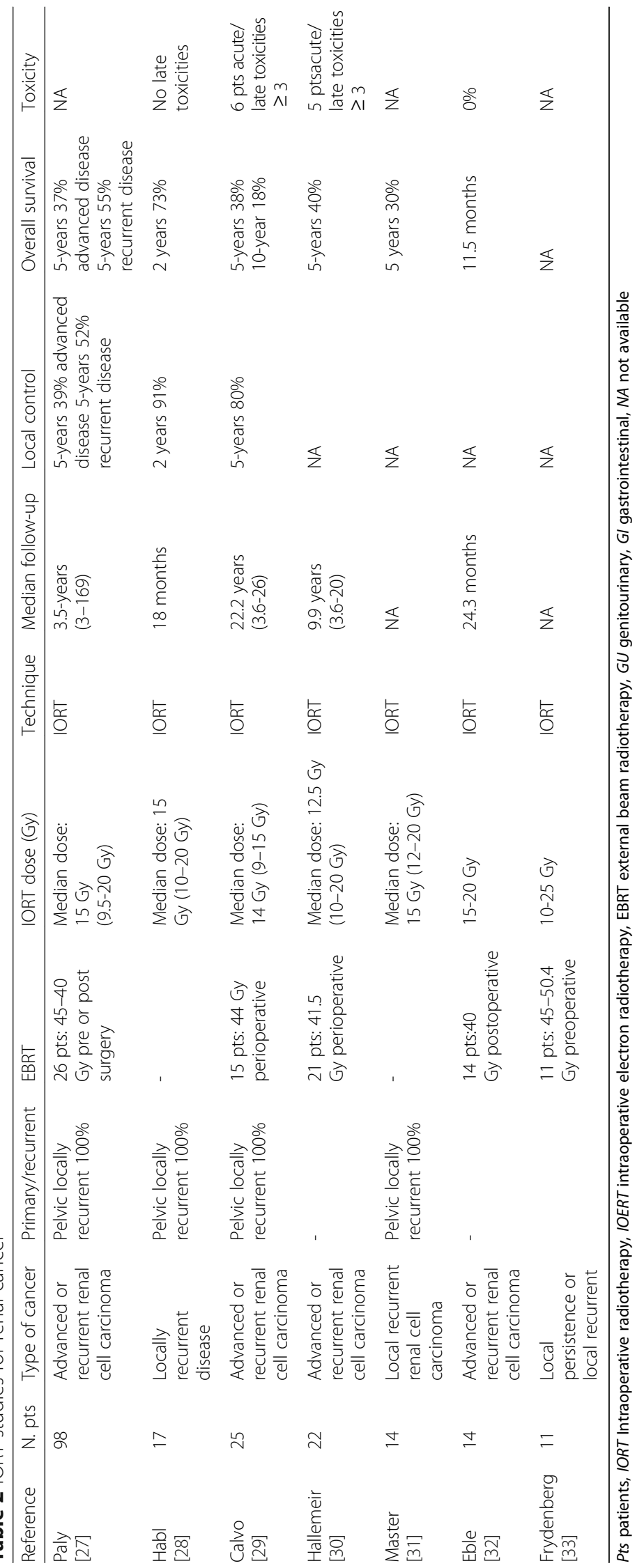


Table 3 IORT studiesfor bladder cancer

\begin{tabular}{|c|c|c|c|c|c|c|c|}
\hline Reference & N. pts & Stage & EBRT & Treatment & Local control (5 years) & Overall survival 5-years & Toxicity \\
\hline Hallemeier [35] & 11 & Local recurrence & Neoadjuvant & $\begin{array}{l}\text { Surgery + IORT } \\
(12.5 \mathrm{~Gy})\end{array}$ & $51 \%$ & $16 \%$ & NA \\
\hline Koning [36] & 1040 & $\mathrm{~T} 1-\mathrm{T} 2$ & Neoadjuvant & $\begin{array}{l}\text { surgery, Ir-192 } \\
(25-40 \text { Gy) }\end{array}$ & $75 \%$ & $62 \%$ & $\begin{array}{l}\text { Fistula 24, ulcers/ } \\
\text { necroses } 144\end{array}$ \\
\hline van Onna [37] & 111 & $\mathrm{~T} 1-\mathrm{T} 2$ & Neoadjuvant & Ir-192 (40 Gy) & NA & $70 \%$ & $\begin{array}{l}\text { Fistula } 5 \\
\text { GU } 5\end{array}$ \\
\hline $\begin{array}{l}\text { van der Steen-Banasik } \\
\text { [38] }\end{array}$ & 76 & $\mathrm{~T} 1-\mathrm{T} 2$ & Neoadjuvant & $\begin{array}{l}\text { Cs-137, Ir-192 } \\
\text { (30-60 Gy) }\end{array}$ & $70 \%$ & $57 \%$ & NA \\
\hline Blank [39] & 122 & T1-T2-T3 & Neoadjuvant & $\begin{array}{l}\text { Ir-192 (20- } \\
70 \mathrm{~Gy})\end{array}$ & $76 \%$ & $73 \%$ & GU 5 \\
\hline Nieuwenhuijzen [40] & 108 & $\mathrm{~T} 1-\mathrm{T} 2$ & Neoadjuvant & $\mid r-192$ & $73 \%$ & $62 \%$ & NA \\
\hline De Crevoisier [41] & 58 & T1-T2-T3 & Neoadjuvant & $\begin{array}{l}\text { surgery, Ir-192 } \\
(60 \mathrm{~Gy})\end{array}$ & $65 \%$ & $60 \%$ & $\begin{array}{l}5 \text { major late } \\
\text { toxicities }\end{array}$ \\
\hline Gerard [42] & 27 & $\mathrm{~T} 2, \mathrm{~T} 3$ & No & Surgery + IORT & $85 \%$ & $53 \%$ & NA \\
\hline Pernot [43] & 82 & $\mathrm{~T} 1, \mathrm{~T} 2, \mathrm{~T} 3, \mathrm{~T} 4, \mathrm{Tx}$ & Neoadjuvant & $\begin{array}{l}\text { surgery Ir-192 } \\
\text { (30-50 Gy }\end{array}$ & $78 \%$ & $73 \%$ & 7 late toxcities $\geq \mathrm{G} 3$ \\
\hline Calvo [44] & 40 & $\mathrm{~T} 2, \mathrm{~T} 3, \mathrm{~T} 4$ & Neoadjuvant & $\begin{array}{l}\text { surgery + IORT } \\
(15 \mathrm{~Gy})\end{array}$ & NA & $68 \%$ & NA \\
\hline Rozan [45] & 205 & T1-T2-T3 & Neoadjuvant & $\begin{array}{l}\text { surgery Ir-192 } \\
(30-50 \mathrm{~Gy}\end{array}$ & NA & $\begin{array}{l}77.4 \% \mathrm{~T} 1,62.9 \% \mathrm{~T} 2, \\
46.8 \% \mathrm{~T} 3\end{array}$ & $\begin{array}{l}\text { haematuria, fistula, } \\
\text { chronic cystitis } 29\end{array}$ \\
\hline Batterman [46] & 85 & $\mathrm{~T} 2$ & Neoadjuvant & Ra-226 & $74 \%$ & $55 \%$ & NA \\
\hline Mazeron [47] & 24 & $\mathrm{~T} 2$ & Adjuvant & surgery, Ir-192 & $92 \%$ & $58 \%$ & NA \\
\hline $\begin{array}{l}\text { van der Werf-Messing } \\
{[48]}\end{array}$ & 328 & $\mathrm{~T} 2$ & Neoadjuvant & Ra-226 & $77 \%$ & $56 \%$ & NA \\
\hline Matsumoto [49] & 28 & $\mathrm{~T} 2$ & Adjuvant & IORT & $82 \%$ & $62 \%$ & NA \\
\hline
\end{tabular}

Pts patients, EBRT External beam radiation therapy, Ra-226 brachytherapy, radium needles, Ir-192 brachytherapy, afterloading iridium, IORT intraoperative electron radiation therapy

by the addition of neoadjuvant chemotherapy. This finding can be of importance with respect to the development of new protocols aiming at bladder preservation. In the Lyon series [42], an excellent bladder preservation rate of $69 \%$ was achieved with the combination of preoperative chemo-RT followed by IORT. This is the only prospective study about IORT in bladder carcinoma. It could be of interest to attempt verifying these results in further studies using an IORT approach.

In conclusion, after a careful patients selection, IORT could be used within a bladder sparing multidisciplinary approach because of the favourable 5-year local control rates aiming at escalating the radiation dose. IORT might have a role also in case of radical surgery for locally advanced disease in order to improve local control rates, as performed in the Pamplona's series. Multicentric prospective studies could useful to confirm the role of IORT in this tumour setting.

\section{Prostate cancer}

The rationale for dose escalation with IORT in prostate cancer is based on the demonstration of a dose-response relationship and a low $\alpha / \beta$ value in the radiobiological linear quadratic model [51]. Likewise, the exploitation of this principle is being increasingly investigated in EBRT with hypofractionation [52].

Among 14 IORT literature studies, 9 clinical series and the ISIORT registry were selected and presented in Table 4 [2, 53-61].

Early data on IORT in prostate cancer came from the Kyoto University and the Saitama Cancer Centre in Japan, where the authors treated patients through a perineal IORT approach without prostatectomy $[59,61]$. More recent experiences were reported by Italian authors using IORT in combination with radical prostatectomy and regional lymph node dissection before or after the surgical procedure [53-56]. A relevant percentage (81\%) of patients was included in prospective institutional study protocols as described in the ISIORT data-registry [2]. From this analysis, it emerged that IORT was used as a boost dose prior to prostate removal in most cases. When a single-shot radiation strategy was adopted, a dose of 18-21 Gy was delivered, similarly to the breast cancer model. The diameter and bevel end angle of the applicators were selected based on target dimensions, considering a margin of at least $5 \mathrm{~mm}$ around the prostate and the necessity to reach the target underneath the pubic arch while sparing the bladder. The electron beam energy, between 9 and $12 \mathrm{MeV}$, depended on 
Table 4 IORT studies for prostate cancer

\begin{tabular}{|c|c|c|c|c|c|c|c|c|c|}
\hline Reference & N. pts & Patients' selection & Surgical approach & IORT dose (Gy) & Technique & Adjuvant EBRT & BRFS & Overall survival & Toxicity \\
\hline $\begin{array}{l}\text { Krengli (ISIORT) } \\
\text { [2] }\end{array}$ & 108 & $\begin{array}{l}\text { Intermediate-high } \\
\text { risk }^{\mathrm{a}}\end{array}$ & NA & $\begin{array}{l}\text { 8-15 Gy with } \\
\text { EBRT 18-21 } \\
\text { Gy single shoot }\end{array}$ & $\begin{array}{l}\text { IORT or } \\
50-\mathrm{KV}\end{array}$ & NA & NA & NA & NA \\
\hline Krengli [53] & 38 & $\begin{array}{l}\text { Intermediate-high } \\
\text { risk }^{\mathrm{a}}\end{array}$ & $\begin{array}{l}\text { Retropubic approach } \\
\text { IORT + Prostatectomy }\end{array}$ & 10-12 Gy & IORT & $\begin{array}{l}46-50 \mathrm{~Gy} \\
2 \mathrm{~Gy} / \mathrm{fx}\end{array}$ & $82 \%$ & 2 -years $100 \%$ & $\begin{array}{l}\text { Lymphocele } 16 \% \\
\text { hematoma } 6 \%\end{array}$ \\
\hline Rocco [54] & 33 & $\begin{array}{l}\text { Intermediate-high } \\
\text { risk }^{\mathrm{a}}\end{array}$ & $\begin{array}{l}\text { Retropubic approach } \\
\text { IORT + Prostatectomy }\end{array}$ & 12 Gy & IORT & $\begin{array}{l}45 \mathrm{~Gy}, 1.8 \\
\mathrm{~Gy} / \mathrm{fx}\end{array}$ & $97 \%$ & 2 -years 100\% & $\begin{array}{l}\text { GU: } 17 \% \geq G 2 \\
\text { Gl: } 10 \% \geq G 2\end{array}$ \\
\hline Saracino [55] & 34 & Intermediate risk ${ }^{\mathrm{a}}$ & $\begin{array}{l}\text { Retropubic approach } \\
\text { Prostatectomy + IORT }\end{array}$ & 16-22 Gy & IORT & No & $77 \%$ & NA & $\begin{array}{l}\text { No GU/Gl } \\
\text { toxicities } \geq \text { G1 }\end{array}$ \\
\hline Orecchia [56] & 11 & High-risk $^{a}$ & $\begin{array}{l}\text { Retropubic approach } \\
\text { IORT + Prostatectomy }\end{array}$ & 12 Gy & IORT & $\begin{array}{l}45 \mathrm{~Gy}, 1.8 \\
\mathrm{~Gy} / \mathrm{fx}\end{array}$ & NA & NA & $\begin{array}{l}\text { No GU/Gl } \\
\text { toxicities } \geq \mathrm{G} 1\end{array}$ \\
\hline Kato [57] & 54 & Stage $B 2-D 1^{b}$ & $\begin{array}{l}\text { Perineal/retropubic } \\
\text { No prostatectomy }\end{array}$ & 25-30 Gy & IORT & $\begin{array}{l}30 \mathrm{~Gy}, 2 \\
\mathrm{~Gy} / \mathrm{fx}\end{array}$ & $74 \%$ & NA & Early Gl G3: 7\% \\
\hline Higashi [58] & 35 & Stage $B-C^{b}$ & $\begin{array}{l}\text { Perineal/retropubic } \\
\text { No prostatectomy }\end{array}$ & 25-30 Gy & IORT & $\begin{array}{l}30 \mathrm{~Gy}, 2 \\
\mathrm{~Gy} / \mathrm{fx}\end{array}$ & NA & $\begin{array}{l}5 \text {-years 87\% } \\
\text { (stage C) } \\
5 \text {-years 92\% } \\
\text { (stage B) }\end{array}$ & NA \\
\hline Abe [59] & 21 & Stage B2-days ${ }^{b}$ & Perineal & $\begin{array}{l}\text { 28-35 Gy or } \\
20-25 \text { Gy } \\
\text { (if combined } \\
\text { with EBRT) }\end{array}$ & IORT & $50 \mathrm{~Gy}$ & NA & 5 -years $72 \%$ & $\begin{array}{l}\text { GU: } 100 \% \text { early } \\
\text { ematuria } 10 \% \\
\text { early pollakiuria }\end{array}$ \\
\hline Kojima [60] & 30 & Stage B-C ${ }^{b}$ & $\begin{array}{l}\text { Perineal/retropubic } \\
\text { No prostatectomy }\end{array}$ & - & IORT & NA & NA & 5 -years $43 \%$ & NA \\
\hline Takahashi [61] & 14 & Stage B2-days ${ }^{b}$ & $\begin{array}{l}\text { Perineal } \\
\text { No prostatectomy }\end{array}$ & $\begin{array}{l}\text { 28-35 Gy or } \\
20-25 \text { Gy } \\
\text { (if combined } \\
\text { with EBRT) }\end{array}$ & IORT & $50 \mathrm{~Gy}$ & NA & NA & $0 \%$ \\
\hline
\end{tabular}

pts patients, GU genito-urinary, GI gastro-intestinal, BRFS biochemical relapse-free survival, NA not available

${ }^{a}$ National Comprehensive Cancer Network (NCCN) guidelines NCCN [6]

${ }^{b}$ Whitemore-Jewett staging system [Whitmore 1956, Jewett 1975]

the depth of the target and the position of the rectum, which should be spared.

Patient selection varied widely in the various studies. The Japanese series included either early or advanced stage disease and in particular the Kyoto University included stages from A2 to $\mathrm{C}$ treated with curative intent and even stage D2 treated with palliative intent $[59,61]$. The Italian studies accrued only non-metastatic locally advanced disease based on the identification of preoperative risk factors.

In terms of post-surgical early and late side effects, IORT for prostate cancer resulted an acceptable procedure. In the Japanese series, toxicity resulted in early haematuria, pollakiuria but only very few cases of late chronic cystitis and urethral stricture. Interestingly, Kato et al. reported a reduction in rectal toxicity by using a spacer to reduce the dose to the anterior rectal wall [57].

In the Italian series, surgical complications, such as haematoma and lymphocele, occurred with a similar incidence to that of conventional prostatectomy [53-56]. No major surgical complications were described and patients had no significant difference of estimated blood loss and need of transfusion. In this regard, Rocco et al. reported post-surgical complications in $42 \%$ of patients after surgery and IORT and in 30\% after prostatectomy alone [54].

Although the relatively short follow-up, the outcome in terms of biochemical disease free survival was quite promising resulting higher than $70 \%$ in both the Japanese and Italian series (Table 4). Of note, a recent update of our clinical series of 95 patients showed a 5 -years biochemical disease-free survival rate of $78 \%$ in high-risk patients (oral presentation at ISIORT-ESTRO Forum, Barcelona, 24-28 April, 2015).

Clinical trials with long follow-up are needed to assess the real efficacy of IORT in locally advanced prostate cancer but preliminary results look quite promising. The best candidates for IORT possibly combined with EBRT, could be the patients staged T3N0 with high risk for positive margins. In the future, multicentre studies should be designed to better clarify the real role of IORT for dose escalation in local advanced prostate cancer patients.

\section{Conclusions}

The delivery of a high single dose of radiation to a limited volume during the surgical time, achievable with IORT, is 
useful to avoid normal tissues not at risk of microscopic disease. For gynaecological and genito-urinary cancers, IORT is not a standard treatment but it may be considered a treatment option in selected patients.

In endometrial, cervical and renal cancers, IORT can be used mainly in recurrent disease, whereas in bladder carcinoma it may be part of an organ-sparing treatment approach aiming at patient quality of life preservation. In the case of prostate cancer, IORT can be used in locally advanced high risk disease possibly combined with EBRT to intensify the radiation dose in the attempt to improve long term local control and possibly increase biochemical disease-free and overall survival.

The available literature data are interesting but the present review shows that the majority of published clinical studies are mono-institutional, retrospective and often included a limited number of patients. In order to overcome these limitations, large multicentre collaborations should be established to design prospective clinical trials aiming at better defining the role of IORT in tailored multimodality therapeutic approaches for gynaecological and genito-urinary tumours. For this purpose, the ISIORT could serve as a basis for future collaboration and the ISIORT-Registry could be a platform for sharing data and promote clinical research.

\section{Abbreviations}

CTV: Clinical target volume; EBRT: External beam radiotherapy; IOHDR: Intra Operative high dose rate; IORT: Intraoperative radiotherapy;

ISIORT: International society of intraoperative radiation therapy;

RT: Radiotherapy

\section{Acknowledgements}

The "Lega Italiana per la lotta contro i tumori LILT (Italian league against cancer)", Section of Vercelli, Italy supported the work of LD.

\section{Funding}

This study was not supported by outside funding.

\section{Authors' contributions}

MK developed the design of the review and contributed to draft and revise the manuscript. CP and LD performed the literature search and analysis, and contributed to draft the manuscript. DS, AV, NS and CT contributed to the study design and to revise critically the manuscript. All the authors read and approved the final version of the manuscript.

\section{Competing interests}

The authors declare no conflict of interest.

\section{Consent for publication}

Not applicable.

Ethics approval and consent to participate Not applicable.

\section{Author details}

${ }^{1}$ Department of Translational Medicine, University of Piemonte Orientale, Via Solaroli, 17-28100 Novara, Italy. ${ }^{2}$ Department of Radiotherapy, University Hospital Maggiore della Carità, Novara, Italy. ${ }^{3}$ Department of Obstetrics and Gynecology, University Hospital Maggiore della Carità, Novara, Italy. ${ }^{4}$ Department of Urology, University Hospital Maggiore della Carità, Novara, Italy.
Received: 5 January 2016 Accepted: 21 December 2016

Published online: 19 January 2017

\section{References}

1. Comas C, Prio A. Irradiation roentgen preventive intraabdominale, après l'intervention chirurgicale dans un cas de cancer de l'uterus. In: Pesented at the Congres International d'Electrologie. Barcelona: Imprenta Francesca Badia; 1906.

2. Krengli M, Calvo FA, Sedlmayer F, Sole CV, Fastner G, Alessandro M, et al. Clinical and technical characteristics of intraoperative radiotherapy. Analisys of ISIORT-Europe database. Strahlenther Onkol. 2013;189:739-7.

3. Krengli M, Sedlmayer F, Calvo FA, Sperk E, Pisani C, Sole CV, et al. ISIORT pooled analysis 2013 update: clinical and technical characteristics of intraoperative radiotherapy. Translat Cancer Res. 2014;3:48-58.

4. Haddock MG, Martinez-Monge R, Petersen IA, Wilson TO. Locally advanced primary and recurrent gynecological malignancies: EBRT with or without IOERT or HDR-IORT. In: Gunderson LL, Willett CG, Calvo FA, Harrison LB, editors. Intraoperative irradiation. Techniques and results. 2nd ed. New York: Humana Press, Springer; 2011.

5. Backes FJ, Martin DD. Intraoperative radiation therapy (IORT) for gynecologic malignancies. Gynecol Oncol. 2015;138:449-56.

6. National Comprehensive Cancer Network (NCCN), Clinical Practice Guidelines in Oncology, Uterine and Cervical Cancer, Version 2.2015

7. Sole CV, Calvo FA, Lozano MA, Gonzalez-Bayon L, Gonzalez-Sansegundo C, Alvarez $\mathrm{A}$, et al. External-beam radiation therapy after surgical resection and intraoperative electron-beam radiation therapy for oligorecurrent gynecological cancer. Long-term outcome. Strahlenther Onkol. 2014;190:171-80.

8. Foley OW, Rauh-Hain JA, Clark RM, Goodman A, Growdon WB, Boruta DM, Schorge JO, Del Carmen MG. Intraoperative Radiation Therapy in the Management of Gynecologic Malignancies. Am J Clin Oncol. 2016;39:329-34.

9. Backes FJ, Billingsley CC, Martin DD, Tierney BJ, Eisenhauer EL, Cohn DE, et al. Does intra-operative radiation at the time of pelvic exenteration improve survival for patients with recurrent, previously irradiated cervical, vaginal, or vulvar cancer? Gynecol Oncol. 2014;135:95-9.

10. Barney BM, Petersen IA, Dowdy SC, Bakkum-Gamez JN, Klein KA, Haddock MG. Intraoperative electron beam radiotherapy (IOERT) in the management of locally advanced or recurrent cervical cancer. Radiat Oncol. 2013;8:80.

11. Calvo FA, Sole CV, Lozano MA, Gonzalez-Bayon L, Gonzalez-Sansegundo C, Alvarez A, et al. Intraoperative electron beam radiotherapy and extended surgical resection for gynecological pelvic recurrent malignancies with and without external beam radiation therapy: long-term outcomes. Gynecol Oncol. 2013;130:537-44

12. Giorda G, Boz G, Gadducci A, Lucia E, De Piero G, De Paoli A, et al. Multimodality approach in extra cervical locally advanced cervical cancer: chemoradiation, surgery and intra-operative radiation therapy. A phase II trial. Eur J Surg Oncol. 2011;37:442-7.

13. Tran PT, Su Z, Hara W, Husain A, Teng N, Kapp DS. Long-Term Survivors Using Intraoperative Radiotherapy For recurrent Gynecologic Malignancies. Int J Radiat Oncol Biol Phys. 2007;69:504-11.

14. Dowdy SC, Mariani A, Cliby WA, Haddock MG, Petersen IA, Sim FH, et al. Radical pelvic resection and intraoperative radiation therapy for recurrent endometrial cancer: technique and analysis of outcomes. Gynecol Oncol. 2006;101:280-6.

15. Awtrey CS, Cadungog MG, Leitao MM, Alektiar KM, Aghajanian C, Hummer AJ, et al. Surgical resection of recurrent endometrial carcinoma. Gynecol Oncol. 2006;102:480-88.

16. Martinez-Monge R, Jurado M, Aristu JJ, Moreno M, Cambeiro M, PerezOchoa A, et al. Intraoperative electron beam radiotherapy during radical surgery for locally advanced and recurrent cervical cancer. Gynecol Oncol. 2001;82:538-43.

17. Gemignani ML, Alektiar KM, Leitao M, Mychalczak B, Chi D, Venkatraman E, et al. Radical surgical resection and high-dose intraoperative radiation therapy (HDR-IORT) in patients with recurrent gynecologic cancers. Int J Radiat Oncol Biol Phys. 2001;50:687-94.

18. del Carmen MG, McIntyre JF, Fuller AF, Nikrui N, Goodman A. Intraoperative Radiation Therapy in the Treatment of PelvicGynecologic Malignancies: A Review of Fifteen Cases. Gynecol Oncol. 2000;79:457-62.

19. Garton GR, Gunderson LL, Webb MJ, Wilson TO, Martenson JA, Cha SS, et al. Intraoperative radiation therapy in gynecologic cancer: update of the experience at a single institution. Int J Radiat Oncol Biol Phys. 1997;37:839-43. 
20. Mahe MA, Gerard JP, Dubois JB, Roussel A, Bussieres E, Delannes M, et al. Intraoperative radiation therapy in recurrent carcinoma of the uterine cervix: report of the French intraoperative group on 70 patients. Int J Radiat Oncol Biol Phys. 1996;34:21-6.

21. Stelzer KJ, Koh WJ, Greer BE, Cain JM, Tamimi HK, Figge DC, et al. The use of intraoperative radiation therapy in radical salvage for recurrent cervical cancer: outcome and toxicity. Am J Obstet Gynecol. 1995;172:1881-6.

22. Berek JS, Howe C, Lagasse LD, Hacker NF. Pelvic exenteration for recurrent gynecologic malignancy: survival and morbidity analysis of the 45-year experience at UCLA. Gynecol Oncol. 2005;99:153-9.

23. Petignat $P$, Jolicoeur $M$, Alobaid A, Drouin P, Gauthier P, Provencher $D$, et al. Salvage treatment with high-dose-rate brachytherapy for isolated vaginal endometrial cancer recurrence. Gynecol Oncol. 2006;101:445-9.

24. Kramar A, Negrier S, Sylvester R, Joniau S, Mulders P, Powles T, et al. Guidelines for the definition of time-to-event end points in renal cell cancer clinical trials: results of the DATECAN project. Ann Oncol. 2015;00:1-7.

25. Renal Cell Cancer Treatment (PDQ ${ }^{\circledR}$ )-Health Professional Version 2016. Available fromhttps://www-ncbi-nlm-nih-gov.bvs.clas.cineca.it/books/NBK65815/.

26. Zelefsky MJ, Greco C, Motzer R, Magsanoc JM, Pei X, Lovelock M, et al. Tumor control outcomes after hypofractionated and single-dose stereotactic image-guided intensity-modulated radiotherapy for extracranial metastases from renal cell carcinoma. Int J Radiat Oncol Biol Phys. 2012;82:1744-8

27. Paly JJ, Hallemeir CL, Biggs PJ, Niemierko A, Roeder F, Martínez-Monge R, et al. Outcomes in a Multi-institutional Cohort of Patients Treated With Intraoperative Radiation Therapy for Advanced or Recurrent Renal Cell Carcinoma. Int J Radiat Oncol Biol Phys. 2014;88:618-23.

28. Habl G, Uhl M, Hensley F, Pahernik S, Debus J, Roder F. Intraoperative electron radiation therapy (IOERT) in patients with locally recurrent renal cell carcinoma. Radiat Oncol. 2013;8:282.

29. Calvo FA, Sole CV, Martinez-Monge R, Azinovic I, Aristu J, Zudaire J, et al. Intraoperative EBRT and resection for renal cell carcinoma: twenty-year outcomes. Strahlenther Onkol. 2013;189:129-36.

30. Hallemeier CL, Choo R, Davis BJ, Pisansky TM, Gunderson LL, Leibovich BC, et al. Long-term outcomes after maximal surgical resection and intraoperative electron radiotherapy for locoregionally recurrent or locoregionally advanced primary renal cell carcinoma. Int J Radiat Oncol Biol Phys. 2012:82:1938-43.

31. Master VA, Gottschalk A, Kane C, Carroll PR. Management of isolated renal fossa recurrence following radical nephrectomy. J Urol. 2005;174:473-7.

32. Eble MJ, Staehler G, Wannenmacher M. The intraoperative radiotherapy (IORT) of locally spread and recurrent renal-cell carcinomas. Strahlenter Onkol. 1998;174:30-6.

33. Frydenberg M, Gunderson L, Hahn G, Fieck J, Zincke H. Preoperative external beam radiotherapy followed by cytoreductive surgery and intraoperative radiotherapy for locally advanced primary or recurrent renal malignancies. J Urol. 1994;152:15-21.

34. Rouprêt M, Babjuk M, Compérat E, Zigeuner R, Sylvester RJ, et al. European Association of Urology Guidelines on Upper Urinary Tract Urothelial Cell Carcinoma: 2015 Update. Eur Urol. 2015;68:868-79.

35. Hallemier CL, Karnes RJ, Pisansky TM, Davis BJ, Gunderson LL, Leibovich BC, et al. Multimodality therapy including surgical resection and intraoperative electron radiotherapy for recurrent or advanced primary carcinoma of the urinary bladder or ureter. Am J Clin Oncol. 2013;36:596-600.

36. Koning CCE, Blank LECM, Koedooder C, van Os RM, van de Kar M, Jansen

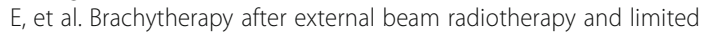
surgery preserves bladders for patients with solitary pT1-pT3 bladder tumors. Ann Oncol. 2012;23:2948-53.

37. van Onna IE, Oddens JR, Kok ET, van Moorselaar RJ, Bosch JL, Battermann JJ. External Beam Radiation Therapy Followed by Interstitial Radiotherapy with Iridium-192 for Solitary Bladder Tumours: Results of 111 Treated Patients. Eur Urol. 2009:56:113-22

38. van der Steen-Banasik E, Ploeg M, Witjes JA, van Rey FS, Idema JG, Heijbroek RP. Brachytherapy versus cystectomy in solitary bladder cancer: A case control, multicentre, East-Netherlands study. Radiother Oncol. 2009;93:352-7.

39. Blank LE, Koedooder K, van Os R, van de Kar M, van der Veen JH, Koning CC. Results of bladder-conserving treatment, consisting of brachytherapy combined with limited surgery and external beam radiotherapy, for patients with solitary T1-T3 bladder tumors less than $5 \mathrm{~cm}$ in diameter. Int J Radiat Oncol Biol Phys. 2007;69:454-8.
40. Nieuwenhuijzen JA, Pos F, Moonen LMF, Hart AA, Horenblas S. Survival after bladder-preservation with brachytherapy versus radical cystectomy; a single institution experience. Eur Urol. 2005;48:239-45.

41. de Crevoisier R, Ammor A, Court B, Wibault P, Chirat E, Fizazi K, et al. Bladder-conserving surgery and interstitial brachytherapy for lymph node negative transitional cell carcinoma of the urinary bladder: results of a 28-year single institution experience. Radiother Oncol. 2004;72:147-57.

42. Gerard JP, Hulewicz G, Marechal JM, Dubernard P, Ayzac L, Gilly FN, et al. Pilot study of IORT for bladder carcinoma. Front Radiat Ther Oncol. 1997;31:250-2.

43. Pernot M, Hubert J, Guillemin F, Six A, Hoffstetter S, Peiffert D, et al. Combined surgery and brachytherapy in the treatment of some cancers of the bladder (partial cystectomy and interstitial iridium-192). Radiother Oncol. 1996:38:115-20.

44. Calvo FA, Aristu J, Abuchaibe O, Rebollo J, Fernandez Hidalgo O, et al. Intraoperative and external preoperative radiotherapy in invasive bladder cancer: effect of neoadjuvant chemotherapy in tumor downstaging. Am J Clin Oncol. 1993;16:61-6.

45. Rozan R, Albuisson E, Donnarieix D, Giraud B, Mazeron JJ, Gerard JP, et al. Interstitial iridium-192 for bladder cancer (a multicentric survey: 205 patients). Int J Radiat Oncol Biol Phys. 1992;24:469-77.

46. Batterman JJ, Tierie AH. Results of implantation for T1 and T2 bladder tumors. Radiother Oncol. 1986;5:85-90.

47. Mazeron JJ, Marinello G, Pierquin B, Le Bourgeois JP, Abbou CC, Auvert J, et al. Treatment of bladder tumors by iridium-192 implantation: the Creteil technique. Radiother Oncol. 1985:4:111-9.

48. van der Werf-Messing B, Menon RS, Hop WL. Cancer of the urinary bladder T2, T3, (NXMO) treated by interstitial radium implant: Second report. Int J Radiat Oncol Biol Phys. 1983;7:481-5.

49. Matsumoto K, Kakizoe T, Mikuriya S, Tanaka T, Kondo I, Umegaki Y. Clinical evaluation of intraoperative radiotherapy for carcinoma of the urinary bladder. Cancer. 1981;47:509-13.

50. Bos MK, Marmolejo RO, Rasch CRN, Pieters BR. Bladder preservation with brachytherapy compared to cystectomy for T1-T3 muscle-invasive bladder cancer: a systematic review. J Contemp Brachyther. 2014;6:191-9.

51. Miralbell R, Roberts SA, Zubizarreta E, Hendry JH. Dose-fractionation sensitivity of prostate cancer deduced from radiotherapy outcomes of 5,969 patients in seven international institutional datasets: $\alpha / \beta=1.4$ (0.9-2.2) Gy. Int J Radiat Oncol Biol Phys. 2012;82:17-24.

52. Vesprini D, Sia M, Lockwood G, Moseley D, Rosewall T, Bayley A, et al. Role of principal component analysis in predicting toxicity in prostate cancer patients treated with hypofractionated intensity-modulated radiation therapy. Int J Radiat Oncol Biol Phys. 2011;81:415-21.

53. Krengli M, Terrone C, Ballarè A, Beldì D, Orecchia R. Intra-operative radiotherapy (IORT) during radical prostatectomy for locally advanced prostate cancer: technical and dosimetrical aspects. Int J Radiat Oncol Biol Phys. 2010;76:1073-7.

54. Rocco B, Jereczek-Fossa B, Matei DV, Verweij F, Santoro L, Vavassori A, et al. Intraoperative radiotherapy during radical prostatectomy for intermediaterisk to locally advanced prostate cancer: treatment technique and evaluation of perioperative and functional outcome vs standard radical prostatectomy, in a matched-pair analysis. BJU Int. 2009;104:1624-30.

55. Saracino B, Gallucci M, De Carli P, Soriani A, Papalia R, Marzi S, et al. Phase I-II study of intraoperative radiation therapy (IORT) after radical prostatectomy for prostate cancer. Int J Radiat Oncol Biol Phys. 2008;71:1049-56.

56. Orecchia R, Jereczek-Fossa BA, Ciocca M, Vavassori A, Cambria R, Cattani F, et al. Intraoperative radiotherapy for locally advanced prostate cancer: treatment technique and ultrasound-based analysis of dose distribution. Anticancer Res. 2007;27:3471-6.

57. Kato S, Sakura M, Kazumoto T. Intraoperative radiation therapy for locally advanced prostate cancer. J Jpn Soc Ther Radiol Oncol. 1998;10:241-8.

58. Higashi Y, Hyochi N, Tari K. Intraoperative radiotherapy combined with external beam radiation for prostate cancer without metastasis. Nippon Rinsho. 1998:56:2177-80.

59. Abe M, Takahashi M, Shibamoto Y, Ono K. Intraoperative radiation therapy for prostatic cancer. Front Radiat Ther Oncol. 1991;35:317-21.

60. Kojima S, Satake I, Tujii T, Tari K, Sakura M. Intraoperative radiotherapy (IORT) in prostatic cancer. Hiyokika Kiyo. 1988;34:1397-402.

61. Takahashi M, Okada K, Shibamoto Y, Abe M, Yoshida O. Intraoperative radiotherapy in the definitive treatment of localized carcinoma of the prostate. Int J Radiat Oncol Biol Phys. 1985;11:147-51. 